\title{
Inflammatory and steroid receptor gene methylation in the human amnion and decidua
}

\author{
Carolyn M Mitchell ${ }^{1,3}$, Shane D Sykes ${ }^{1,3}$, Xin Pan ${ }^{1,3}$, Kirsty G Pringle,3, \\ Eugenie R Lumbers $^{1,3}$, Jonathan J Hirst ${ }^{1,3}$ and Tamas Zakar ${ }^{1,2,3}$ \\ ${ }^{1}$ Mothers and Babies Research Centre, Hunter Medical Research Institute, New Lambton Heights, New South Wales, \\ Australia \\ ${ }^{2}$ Department of Obstetrics and Gynaecology, John Hunter Hospital, Locked Bag 1, Newcastle, New South Wales \\ 2310, Australia \\ ${ }^{3}$ University of Newcastle, Newcastle, New South Wales, Australia
}

Correspondence should be addressed to T Zakar

Email

tamas.zakar@newcastle. edu.au

\begin{abstract}
Correct timing of parturition requires inflammatory gene activation in the gestational tissues at term and repression during pregnancy. Promoter methylation at CpG dinucleotides represses gene activity; therefore, we examined the possibility that DNA methylation is involved in the regulation of labour-associated genes in human pregnancy. Amnion and decidua were collected at 11-17 weeks of gestation and at term following elective Caesarean delivery or spontaneous labour. Methylation of the inflammatory genes PTGS2, $B M P 2, N A M P T$ and $C X C L 2$ was analysed using the Methyl-Profiler PCR System and bisulphite sequencing. Methylation of the glucocorticoid, progesterone and oestrogen receptor genes, involved in the hormonal regulation of gestational tissue function, and the expression of the DNA methyltransferases DNMT1, $-3 A$ and $-3 B$ were also determined. Variable proportions of inflammatory and steroid receptor gene copies, to a maximum of $50.9 \%$, were densely methylated in both tissues consistent with repression. Densely methylated copy proportions were significantly different between genes showing no relationship with varying expression during pregnancy, between tissues and in individuals. Methylated copy proportions of all genes in amnion and most genes in decidua were highly correlated in individuals. DNMT1 and -3A were expressed in both tissues with significantly higher levels in the amnion at 11-17 weeks than at term. We conclude that the unmethylated portion of gene copies is responsible for the full range of regulated expression in the amnion and decidua during normal pregnancy. Dense methylation of individually variable gene copy proportions happens in the first trimester amnion influenced by sequence context and affected strongly by individual circumstances.
\end{abstract}
Key Words
- methylation
- pregnancy
- amnion
- decidua

Journal of Molecular Endocrinology (2013) 50, 267-277

\section{Introduction}

Parturition is associated with inflammation in the fetal membranes and the decidua. Array-based studies assessing the expression of a large number of genes simultaneously as well as studies determining the expression level of proinflammatory candidate genes have shown that the activity of many inflammatory genes increases at term even in the absence of histological inflammation or detectable infectious insult (Haddad et al. 2006, Johnson 
et al. 2006, Mazaki-Tovi et al. 2008, Li et al. 2011, Lim et al. 2012). This changing pattern of gene expression has been described as an 'acute inflammation gene expression signature' (Haddad et al. 2006), which transforms the membranes into an activated state producing uterotonic stimulants such as prostaglandins and undergoing structural remodelling in preparation for rupture during labour. The correct timing of inflammatory fetal membrane activation is critical for normal parturition, as pathological inflammation during pregnancy may cause serious complications such as preterm birth (Marvin et al. 2002, Shankar et al. 2010). The mechanisms that determine the timing of proinflammatory fetal membrane activation and the responsiveness of inflammatory genes to endogenous and exogenous stimuli are essentially unknown.

Stable, but reversible, covalent modifications of DNA and histones control gene transcription potential in eukaryotic cells by shaping the chromatin without altering DNA sequence (Bird 2007, Berger et al. 2009). The best characterised of these modifications is the C5-methylation of cytosine in CpG dinucleotide motifs. Methylation of $\mathrm{CpGs}(\mathrm{meCpG})$ at gene promoters results in transcriptional repression either by interfering with transcription factor binding or by recruiting meCpGbinding proteins that establish a closed chromatin structure (Klose \& Bird 2006). Cell-specific DNA methylation is a key contributor to gene expression patterns that define cell identity (Ehrlich 2003, Straussman et al. 2009). DNA methylation marks are established early during development and maintained by the DNA methyl transferases DNMT3a, $-3 \mathrm{~b}$ and -1 respectively. CpG methylation levels can change, however, in response to developmental and environmental cues, underlying the importance of this chromatin modification in cell differentiation and susceptibility to disease (Bogdanovic \& Veenstra 2009).

Changing CpG methylation is one possible mechanism regulating gene activity in the gestational tissues during pregnancy. It is plausible to hypothesise that methylation may suppress labour-associated inflammatory genes in early pregnancy while loss of methylation increases inflammatory gene expression potential at term and during labour. The aim of the present investigation was to explore this possibility by determining the CpG methylation density in the promoters of four inflammatory genes that show increased expression in the fetal membranes and decidua at term labour. These genes encode prostaglandin endoperoxide synthase-2 (PTGS2, the key prostaglandin biosynthetic enzyme), bone morphogenetic protein-2 (BMP2), nicotinamide phosphoribosyltransferase (NAMPT also called PBEF, or visfatin) and chemokine (C-X-C motif) ligand-2 (CXCL2) (Haddad et al. 2006, Li et al. 2011). We have assessed the methylation status of these genes in amnion collected from normal pregnancies at 11-17 weeks of gestation, at term (37-41 weeks) in the absence of labour and following term labour. Decidua was also analysed from term pregnancies not in labour and following labour. Steroid hormones are fundamentally important regulators of gestational tissue function including inflammatory reactions. The responsiveness to these hormones varies between tissues and changes during pregnancy, which is partially due to changing steroid hormone receptor levels (Sun et al. 1996, Zakar \& Hertelendy 2007, Merlino et al. 2009, Jiang et al. 2012). We have assessed the methylation status of the glucocorticoid receptor (GR, NR3C1), progesterone receptor (PGR, NR3C3) and oestrogen receptor (ESR1, NR3A1) genes in the amnion and decidua to delineate the contribution of receptor gene methylation to the differences in steroid receptor expression levels. In addition, we have measured DNMT1, $-3 A$ and $-3 B$ expression in the same tissues to determine whether varying DNA methyltransferase (DNMT) levels may contribute to the methylation differences observed between gestational tissues, genes and individuals.

\section{Materials and methods}

\section{Patients and tissue collection}

Placentas with attached fetal membranes were collected at the John Hunter Hospital obstetrics ward after deliveries at term either by elective Caesarean section (in the absence of labour, CS, $n=8$ ) or following spontaneous labour $(\mathrm{SL}, n=8)$. All pregnancies were uncomplicated and singleton. Amnion and decidua were isolated from the reflected membranes within $30 \mathrm{~min}$ of birth as described previously (Mitchell \& Powell 1984, Johnson et al. 2002). Amnion tissues were also collected from women undergoing early elective termination between 11 and 17 weeks of pregnancy (ea, $n=8$ ) at a day-surgery. Tissues were snapfrozen in liquid nitrogen and stored at $-80^{\circ} \mathrm{C}$. Exclusion criteria included the presence of clinical or histological inflammation, induced labour or steroid treatment within $24 \mathrm{~h}$ of delivery. Informed written consent was obtained from all participants. Approval of the collection and use of these tissues was granted by the Hunter New England Health Human Ethics Committee and the University of Newcastle Human Ethics Committee.

Published by Bioscientifica Ltd. 


\section{DNA extraction}

DNA was extracted from 20 to $25 \mathrm{mg}$ crushed frozen tissue using the QIAmp DNA Mini Kit (Qiagen). DNA concentration and purity was determined by spectrophotometry (NanoDrop ND-1000, NanoDrop Technologies, Rockland, DE, USA). DNA integrity and fragment size were examined by agarose gel electrophoresis to ascertain whether DNA fragments were in the optimal range of up to $50 \mathrm{~kb}$ in length, with 20-30 kb fragments predominating.

\section{DNA methylation profiling}

Methylation density at target genes was determined by the Methyl-Profiler DNA methylation PCR System (SABiosciences, distributed as EpiTect Methyl qPCR Array by Qiagen Pty Ltd) according to the manufacturer's instructions. This assay uses a combination of methylation-sensitive and methylation-dependent restriction enzymes (provided in the Methyl-Profiler Methylation Enzyme Kit) followed by qPCR analysis of the digestionresistant DNA to quantify the proportion of densely, sparsely and intermediately methylated target sequences in the molecular population present in the DNA sample. The procedure is suitable to perform serial tissue analyses for multiplex gene-specific DNA methylation with high sensitivity and in a convenient bisulphite free manner. Its principle, data analysis method and validation have been described (Ordway et al. 2006, Holemon et al. 2007). For this study, a customised 96-well multiplex assay was developed by the manufacturer based on the genomic sequences of NCBI Homo sapiens Build Number 36 Version 1. The following gene-specific assays were used to construct the customised array: PTGS2, MePH28527-1A; BMP2, MePH25532-1A; NAMPT, MePH10682-1A; CXCL2, MePH06436-1A; GR, MePH28267-1A; PGR, MePH06436-1A and ESR1, MePH28494-1A. The PCR conditions including the primer sequences and amplicon positions have been optimised and are held proprietary by the manufacturer. All screened regions included the transcriptional start site, several hundred base pair sequences upstream and downstream of it and at least one CpG island including or near the transcriptional start site. Further information about each gene-specific assay is available on the SAB-Qiagen website (http://sabiosciences.com/dna_methylation_info.

php? pcatn $=$ [assay i.d.]). The arrays were run on an Applied Biosystems 7500 Real-Time PCR System (Applied Biosystems) using one cycle of $10 \mathrm{~min}$ at $95^{\circ} \mathrm{C}$ to activate the DNA polymerase, followed by 40 cycles of $97^{\circ} \mathrm{C}$ for $15 \mathrm{~s}$ and $72^{\circ} \mathrm{C}$ for $1 \mathrm{~min}$. Dissociation curve analysis followed to confirm homogeneity of the amplification products.

\section{Bisuphite modification and sequence analysis}

Genomic DNA was extracted from $1 \mu \mathrm{g}$ amnion tissue and bisulphite-converted using the Cells-to-CpG Bisulfite Conversion Kit (Life Technologies). PCR amplifications of bisulphite-modified PTGS2 gene sequences were performed with primer sets A, B and C described by Song et al. (2001) using the TopTaq Master Mix Kits (Qiagen) in $50 \mu \mathrm{l}$ reaction volume. PCR conditions included an initial denaturation step at $95^{\circ} \mathrm{C}$ for $5 \mathrm{~min}$, followed by 35 cycles of $94{ }^{\circ} \mathrm{C}$ for $1 \mathrm{~min}, 52^{\circ} \mathrm{C}$ for $1 \mathrm{~min}$ and $72^{\circ} \mathrm{C}$ for $1 \mathrm{~min}$ and a final extension step at $72^{\circ} \mathrm{C}$ for $10 \mathrm{~min}$. The first PCR was performed with primer set $\mathrm{A}$, covering the $869 \mathrm{bp}$ region from -668 to +201 of the PTGS 2 gene (transcription start site is +1$)$. The forward and reverse primer sequences of set A were $5^{\prime}$-TGTATATTGAAGGTAGTTATTTTAT-3' and $5^{\prime}$-ACCAAATACTCACCTATATAACT-3' respectively. Two microlitres of a 20 -fold diluted aliquot of this reaction mixture were used as template for the second PCRs using primer sets $B$ and $C$ nested within the sequence amplified by primer set $\mathrm{A}$. The $\mathrm{B}$ set forward and reverse sequences were $5^{\prime}$-TTGGAGAGGAAGTTAAGTGTTT- ${ }^{\prime}$ and $5^{\prime}$-ATCCCCACTCTCCTATCTAAT- $3^{\prime}$ respectively. The $\mathrm{C}$ set forward sequence was 5'-ATTAGATAGGAGAGTGGGGAT- $3^{\prime}$ and the reverse sequence was 5'-TCTAAAAACGTCTAACTATAAAACT- $3^{\prime}$. The nested PCR products were gel purified with the Wizard SV Gel and PCR Clean-up Kit and cloned using the pGEM-T easy vector system (both from Promega). Plasmid DNA was purified from the white colonies using the GenElute Plasmid Mini Prep Kit (Sigma-Aldrich) and the presence of inserts was verified after digestion with EcoRI. Inserts from six to nine clones from each PCR amplification were sequenced by the Australian Genomic Research Facility (Brisbane, QLD, Australia).

\section{RNA isolation and qRT-PCR analysis}

Total RNA was extracted from $0.2 \mathrm{~g}$ tissue with TRIzol reagent (Life Technologies) according to the manufacturer's instructions. The RNA was purified using RNAsefree DNAse and RNeasy Mini kits (Qiagen) and the quality was assessed by agarose gel electrophoresis. Total RNA $(1 \mu \mathrm{g})$ was converted to cDNA using the Superscript III First Strand Synthesis system and random hexamer primers (Life Technologies). PTGS2, DNMT1, DNMT3A and DNMT3B mRNA abundance was determined by

Published by Bioscientifica Ltd. 
Table 1 qRT-PCR primer sequences and positions

\begin{tabular}{|c|c|c|c|}
\hline Primer & Primer sequence $\left(5^{\prime}-3^{\prime}\right)$ & Position $^{a}$ & GenBank no. \\
\hline DNMT1 & $\begin{array}{l}\text { F: CCTCATTTGCCGAATACATTCTG } \\
\text { R: TCTCCTGCATCAGCCCAAATA }\end{array}$ & $1670 / 1741$ & NM_001130823 \\
\hline DNMT3A & $\begin{array}{l}\text { F: TCCCGGCTCCAGATGTTC } \\
\text { R: CTGGGACAGGTGGGTAAACCT }\end{array}$ & $2145 / 2220$ & NM_175629.1 \\
\hline DNMT3B & $\begin{array}{l}\text { F: CCTCAGTTCCCTCTTGCTCAGT } \\
\text { R: AGCAGCCAGGTCTGATTTGTG }\end{array}$ & $3001 / 3098$ & NM_006892.3 \\
\hline
\end{tabular}

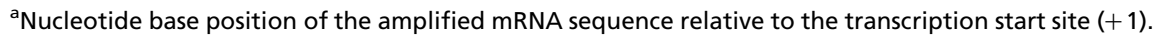

quantitative real-time RT-PCR (qRT-PCR) using an Applied Biosystems 7500 Real-Time PCR System. $\beta$-Actin mRNA was used as the internal reference RNA. The primer sequences, positions and concentrations for PTGS2 mRNA and $\beta$-actin mRNA have been published (Johnson et al. 2002, Mitchell et al. 2011). Primer sequences for DNMT1, DNMT3A and DNMT3B mRNA were designed using Primer Express Software v3.0 (Applied Biosystems) and are listed in Table 1. DNMT primer optimisation was performed in preliminary experiments using RNA from BeWo choriocarcinoma cells, which express the three DNMT mRNAs. The optimised primer concentrations were $1000 \mathrm{nM}$ for DNMT1 and DNMT3A and $800 \mathrm{nM}$ for DNMT3B mRNAs. Amplifications were performed in duplicate with each reaction mix containing SYBR green PCR master mix supplied by Applied Biosystems, primer and template to a total volume of $25 \mu \mathrm{l}$. No-template and no-reverse transcriptase controls were included to test for non-specific amplification and residual DNA template respectively and dissociation curves were examined to ascertain the homogeneity of amplification products.

\section{Statistical analysis}

Primary data generated by the Methyl-Profiler DNA methylation PCR System $\left(C_{\mathrm{T}}\right.$ values with mock, methylation-sensitive, methylation-dependent and doubledigested templates) were imported into the Excel macro spreadsheet provided by the manufacturer. The macro performed quality control of data and quantified the percentage/proportion of densely, intermediately and sparsely methylated template copies in the molecular population of the DNA sample. Assays where delta- $C_{\mathrm{T}}$ values between mock- and double-digests were $\leq 2(\geq 25 \%$ digestion-resistant template), were reported as failures and removed from subsequent analysis. As no intermediately methylated target sequence was detected in any sample (see later), statistics were calculated using the proportion of densely methylated template copies. The data were non-normally distributed; therefore, we employed non-parametric statistic procedures. Comparisons involving more than two groups were performed by Kruskal-Wallis ANOVA followed by pair wise comparisons using the Mann-Whitney $U$ test with Bonferroni-adjusted significance thresholds for multiple comparisons. Two-group comparisons were done with the Mann-Whitney $U$ test. Variances were compared using the Brown \& Forsythe's robust variance test. Relationships were assessed by Spearman rank correlation with Bonferroni-adjusted significance values for multiple comparisons. The relative mRNA abundance for DNMT1, DNMT3A and DNMT3B was determined by the delta- $C_{\mathrm{T}}$ method (Livak \& Schmittgen 2001) with $\beta$-actin mRNA as the reference, and group comparisons were performed as described earlier. The levels of the reference mRNA ( $\beta$-actin) were compared between the gestational groups employing the delta- $C_{\mathrm{T}}$ method using the calibrator sample, which contained $\beta$-actin and was included in all multi-well PCR plates. There was no significant difference between average $\beta$-actin mRNA abundance in amnion from the different gestational groups (ANOVA); however, $\beta$-actin mRNA abundance was $10 \%$ higher in the decidua following SL than in the absence of labour. Relative mRNA abundance values measured in the after-labour decidua samples were therefore multiplied by 1.1 to compensate for this difference in the average reference mRNA level. In all statistical analyses, $P<0.05$ was considered significant. Analyses were carried out using STATA version 11.0 software package (College Station, TX, USA).

\section{Results}

\section{Methylation of inflammatory genes}

We have used the Methyl-Profiler DNA Methylation PCR Array System to assess the methylation status of the genes selected for the study. Methyl-Profiler returns result as the

Published by Bioscientifica Ltd 

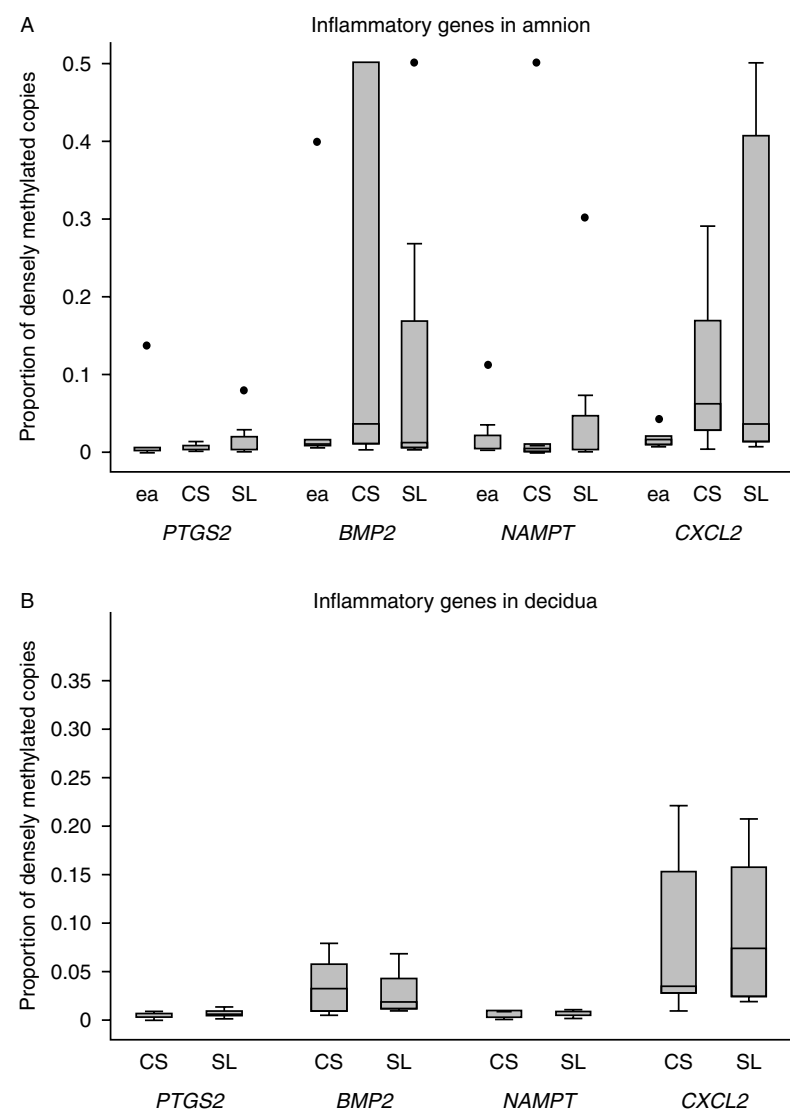

Figure 1

Proportions of densely methylated copies of the PTGS2, BMP2, NAMPT and CXCL2 genes in amnion (A) and decidua (B). Tissues were obtained at 11-13 weeks of pregnancy (ea), after term elective Caesarean delivery (CS) and term spontaneous birth (SL). Boxes span the 25th-75th percentiles with horizontal lines indicating the median, whiskers showing the range of adjacent values and dots showing the outside values. $n=7-8$ per group; there are no significant differences between gestational groups for any gene in both tissues. Variance of CXCL2 methylation increases significantly in amnion with advancing gestation. Methylated copy proportions are significantly different among the genes in both the amnion and the decidua $(P T G S 2=N A M P T<B M P 2=C X C L 2)$

proportion/percentage of densely, intermediately and sparsely methylated target sequences in the DNA samples. A surprisingly consistent feature of the methylation results was that no intermediately methylated sequence was detected in any of the analysed genes in any tissue sample at any gestational state studied. Therefore, the methylation results are presented as proportions of densely methylated sequences, and the rest of the target DNA (1 minus the proportion of densely methylated sequences) is determined as a sparsely methylated or unmethylated molecular population. The box-plots in Fig. 1A and B show the proportions of the densely methylated copies of the inflammatory genes in the amnion and decidua respectively. The proportions varied widely between individuals in the amnion (range: $0-13.56 \%$ for PTGS2 and $0.01-50 \%$ for the other genes) and somewhat less in the decidua (range: $0.02-1.25 \%$ for PTGS2, $0.46-7.78 \%$ for BMP2, $0.06-0.78 \%$ for NAMPT and 0.89-21.94\% for CXCL2). Statistical testing showed, however, that there was no significant difference between gestational groups for any of the genes in the two tissues (Kruskal-Wallis ANOVA and Mann-Whitney $U$ test). The variance of BMP2 and CXCL2 methylation showed a tendency to increase with gestation in the amnion (Fig. 1A), which reached statistical significance in the case of CXCL2 (Brown \& Forsythe's robust variance test). The proportion of densely methylated copies differed significantly between genes in both tissues exhibiting the order $P T G S 2=N A M P T<B M P 2=C X C L 2$ in the amnion as well as in the decidua with data combined

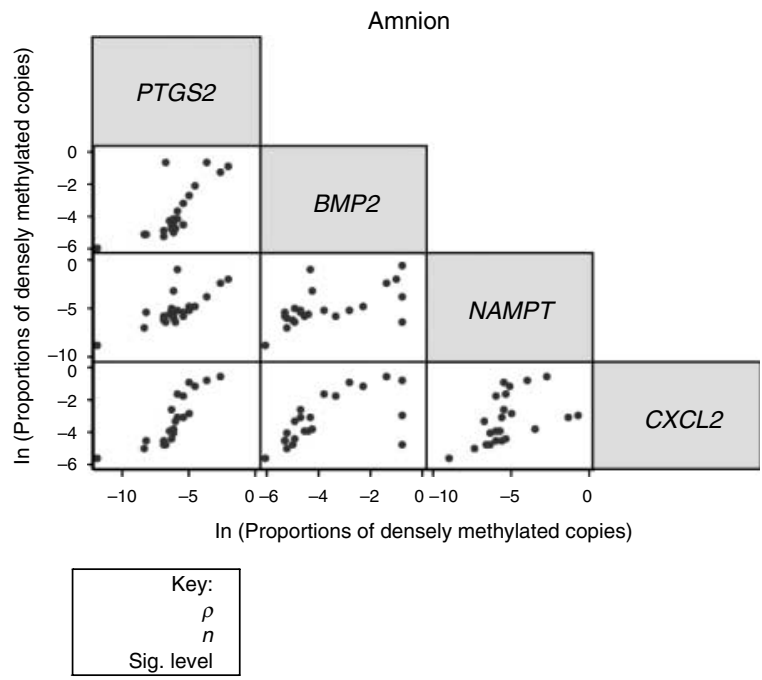

\begin{tabular}{|c|c|c|c|}
\hline PTGS2 & & & \\
\hline $\begin{array}{r}0.7665 \\
22 \\
0.0002\end{array}$ & BMP2 & & \\
\hline $\begin{array}{r}0.7065 \\
23 \\
0.0010\end{array}$ & $\begin{array}{r}0.6152 \\
23 \\
0.0107\end{array}$ & NAMPT & \\
\hline $\begin{array}{r}0.9356 \\
22 \\
0.0000\end{array}$ & $\begin{array}{r}0.7072 \\
22 \\
0.0014\end{array}$ & $\begin{array}{r}0.6739 \\
25 \\
0.0025\end{array}$ & CXCL2 \\
\hline
\end{tabular}

\section{Figure 2}

Correlations of PTGS2, BMP2, NAMPT and CXCL2 densely methylated copy proportions in the amnion. (Upper panel) Correlation matrix with each dot representing a tissue sample on a logarithmic scale. (Lower panel) Spearman correlation analysis results with significance adjusted for multiple comparisons. $\rho$ and $n$ values and significance levels are as shown in the Key. All correlations are significant $(<0.05$, bold). 

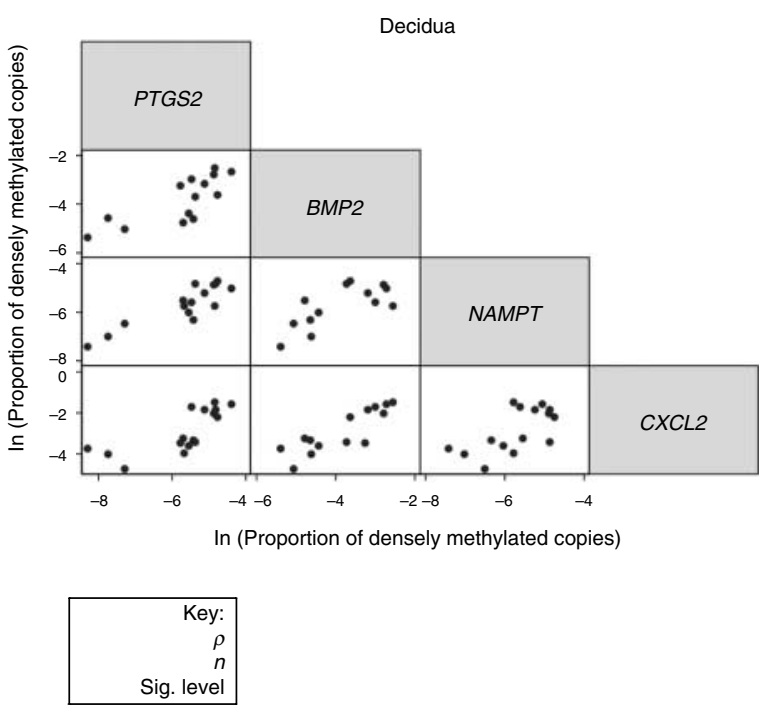

\begin{tabular}{|c|c|c|c|}
\hline PTGS2 & & & \\
\hline $\begin{array}{r}0.7670 \\
14 \\
\mathbf{0 . 0 0 8 2}\end{array}$ & BMP2 & & \\
\hline $\begin{array}{r}0.7882 \\
15 \\
\mathbf{0 . 0 0 2 9}\end{array}$ & $\begin{array}{r}0.5934 \\
13 \\
0.1951\end{array}$ & NAMPT & \\
\hline $\begin{array}{r}0.8088 \\
16 \\
\mathbf{0 . 0 0 0 9}\end{array}$ & $\begin{array}{r}0.8330 \\
14 \\
0.0013\end{array}$ & $\begin{array}{r}0.5576 \\
15 \\
0.1847\end{array}$ & CXCL2 \\
\hline
\end{tabular}

Figure 3

Correlations of PTGS2, BMP2, NAMPT and CXCL2 densely methylated copy proportions in the decidua. (Upper panel) Correlation matrix with each dot representing a tissue sample on a logarithmic scale. (Lower panel) Spearman correlation analysis results with significance adjusted for multiple comparisons. $\rho$ and $n$ values and significance levels are as shown in the Key. Correlations are significant between PTGS2 and the other three genes and between $B M P 2$ and $C X C L 2(<0.05$, bold)

for gestational groups (Kruskal-Wallis ANOVA with multiple comparisons).

As methylated copy proportions varied strongly among individual samples of each tissue, we tested the correlation between the methylation of genes in each individual. Figure 2 shows the scatter plot matrix (with logarithmically transformed data for better visualisation) and the corresponding Spearman correlation data matrix in the amnion sample cohort. Significant positive monotonic relationships were revealed between all combinations of PTGS2, BMP2, NAMPT and CXCL2 densely methylated copy proportions. Similar analysis with decidua (Fig. 3) indicated positive relationships between PTGS2 and the other three genes and between BMP2 and CXCL2. There was no significant relationship between NAMPT and BMP2, or CXCL2 densely methylated copy proportions in the decidua.

\section{Relationship between PTGS2 gene methylation and expression}

The results in Fig. 1 show that PTGS2, BMP2, NAMPT and CXCL2 gene methylation does not change significantly in the gestational groups with advancing pregnancy or labour, although increased expression of these genes has been found in the fetal membranes during the labour-associated inflammatory reaction at term. We have examined the relationship between gene expression and promoter methylation density in individuals by correlating methylated PTGS2 copy proportions with PTGS2 mRNA abundance measured by qRT-PCR in the same amnion samples. The analysis indicated that mRNA abundance and methylated gene copy

A

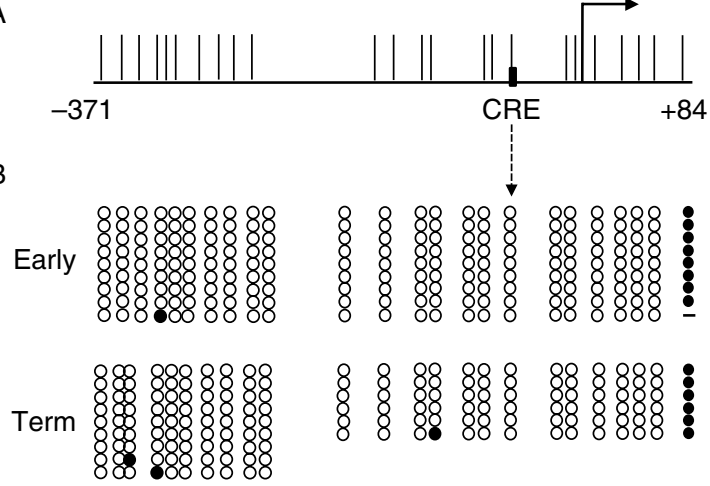

C

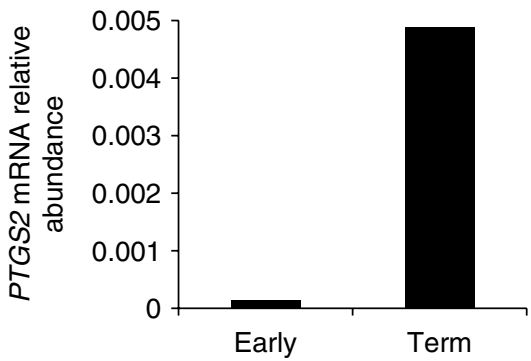

Figure 4

Methylation of CpGs in the promoter and $5^{\prime}$-transcribed regions of the PTGS2 gene in amnion. DNA from an early (Early, 12.7 weeks) and a term gestation (Term) amnion was bisulphite-converted and PCR-amplified using primers recognising bisulphite-modified PTGS2 gene sequences. The amplification products were cloned, sequenced and compared with the unmodified sequence to determine the methylation status of CpG dinucleotides. (A) Scheme of the analysed PTGS2 promoter and $5^{\prime}$-transcribed region spanning the $\mathrm{CpGs}$ between -371 and +84 (relative to the transcriptional start site, +1 , indicated by the arrow). The approximate location of CpG dinucleotides is shown by the vertical lines. The cyclic AMP response element (CRE) is boxed. (B) The methylation status of $\mathrm{CpGs}$ is shown by filled circles (methylated) and empty circles (not methylated). Each horizontal row of circles represents one cloned copy of the PTGS2 gene. The dashed arrow points to the CPG within the CRE. (C) PTGS2 mRNA relative abundance, determined by $q R T-P C R$, in the amnion tissue samples subjected to bisulphite sequencing.

Published by Bioscientifica Ltd. 

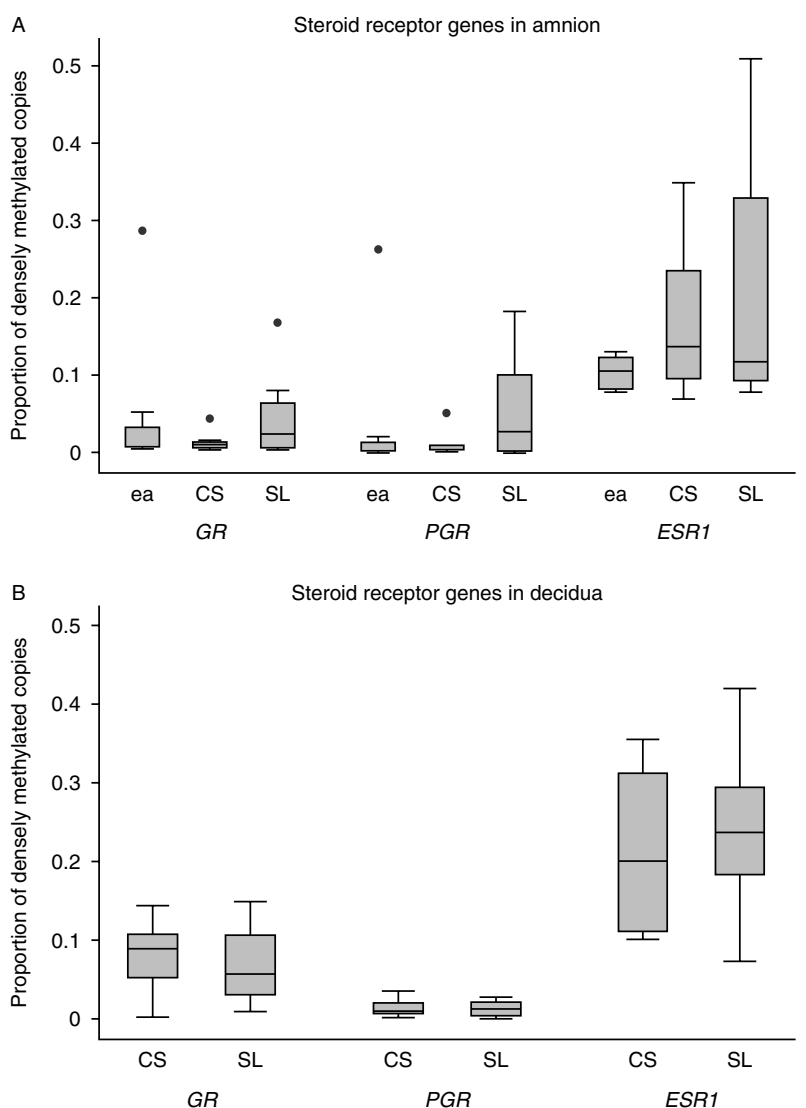

Figure 5

Proportions of densely methylated copies of the GR, PGR and ESR1 genes in amnion (A) and decidua (B). Tissues were obtained at 11-13 weeks of pregnancy (ea), after term elective Caesarean delivery (CS) and term spontaneous birth (SL). Boxes span the 25th-75th percentiles with horizontal lines indicating the median, whiskers showing the range of adjacent values and dots showing the outside values. $n=7-8$ per group; there are no significant differences between gestational groups for any gene in both tissues. The variance of ESR1 methylation increases significantly with advancing gestation in the amnion. Methylated copy proportions are significantly different among the genes in the amnion ( $G R=P G R<E S R 1)$ and the decidua $(P G R<G R<E S R 1)$.

ratios varied independently of each other showing no significant correlation in individuals (Spearman $\rho$ : 0.02, $n=39, P=0.23$ ).

We have also explored the possibility that methylation at single CpG sites may suppress PTGS2 gene expression in early gestation amnion potentially by interfering with transcription factor binding (Tate \& Bird 1993). Methylation of single CpG sites is not expected to change the overall methylation density of CpG islands, detected by the Methyl-Profiler assay. For this purpose, we have selected an early gestation (12.7 weeks) and a term (not in labour) amnion sample and determined the methylation status of $\mathrm{CpG}$ dinucleotides around the transcription start site of the PTGS2 gene by bisulphite sequencing (Fig. 4). The sequenced region spanned nucleotide positions from the $-371 \mathrm{CpG}$ to the +84 CpG relative to the transcription initiation site $(+1)$, containing 24 potentially methylated $\mathrm{CpG}$ dinucleotides (Fig. 4A). One CpG upstream of the transcription initiation site is part of a CRE (cyclic AMP response element), which has been reported critical for PTGS2 expression in amnion cells (Zhu et al. 2009, Guo et al. 2012). Methylation of the CpG within the CRE prevents the binding of the cognate transcription factor rendering CREs inactive (Weih et al. 1991). The results showed that the analysed gene region was very sparsely methylated in all cloned gene copies (Fig. 4B), which was expected considering the Methyl-Profiler data (densely methylated copy proportions were 0.0023 and 0.0018 in the early and term sample respectively). The CpG within the CRE was
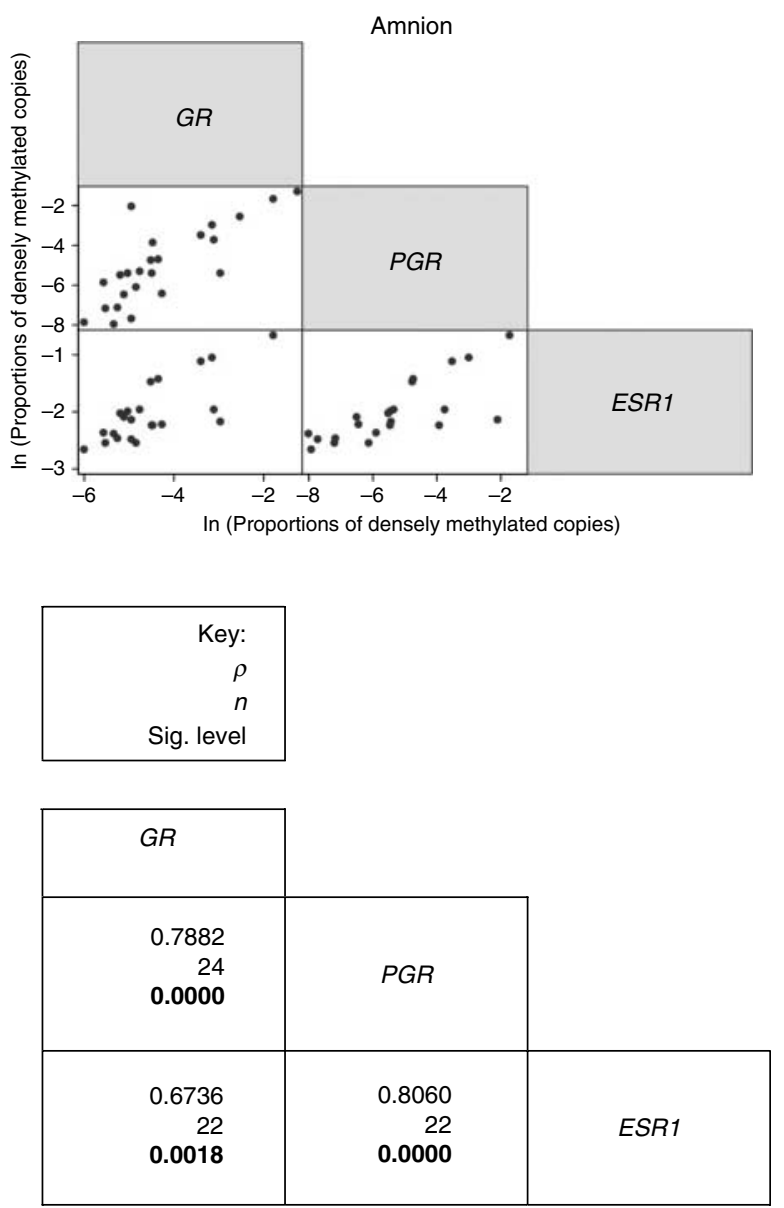

Figure 6

Correlations of GR, PGR and ESR1 densely methylated copy proportions in the amnion. (Upper panel) Correlation matrix with each dot representing a tissue sample on a logarithmic scale. (Lower panel) Spearman correlation analysis results with significance adjusted for multiple comparisons. $\rho$ and $n$ values and significance levels are as shown in the Key. All correlations are significant $(<0.05$, bold $)$.

Published by Bioscientifica Ltd. 


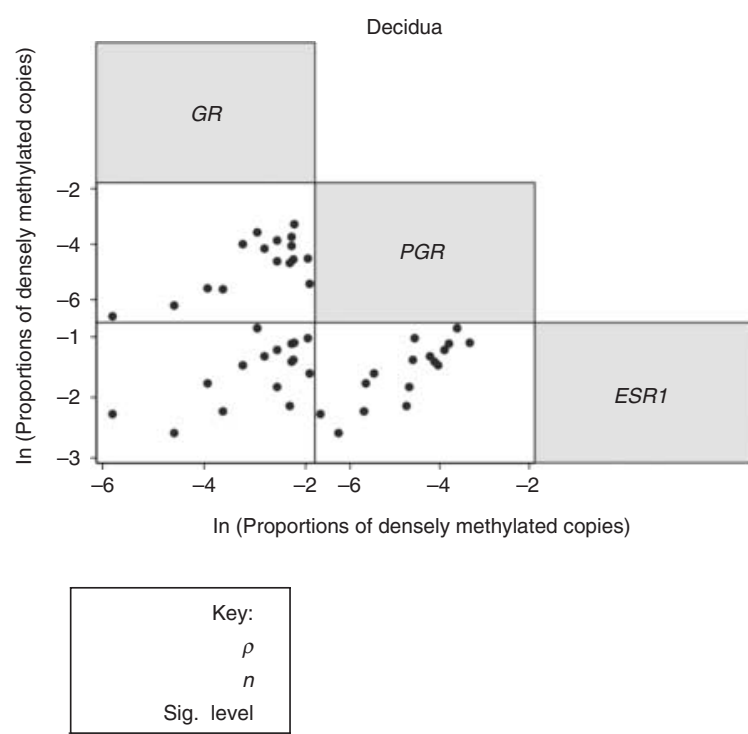

\begin{tabular}{|c|c|c|}
\hline$G R$ & & \\
\hline 0.4771 & \multirow{3}{*}{$P G R$} & \\
\hline 16 & & \\
\hline 0.2476 & & \\
\hline 0.5588 & 0.8735 & \\
\hline 16 & 16 & $E S R 1$ \\
\hline 0.0733 & 0.0000 & \\
\hline
\end{tabular}

Figure 7

Correlations of GR, PGR and ESR1 densely methylated copy proportions in the decidua. (Upper panel) Correlation matrix with each dot representing a tissue sample on a logarithmic scale. (Lower panel) Spearman correlation analysis results with significance adjusted for multiple comparisons. $\rho$ and $n$ values and significance levels are as shown in the Key. Correlation is significant between $P G R$ and ESR1 ( $<0.05$, bold).

unmethylated in both tissues, while the CpG at the +84 position was methylated in all gene copies cloned. There was no methylation difference consistent with the difference between the gestational statuses of the two amnion samples. The level of PTGS2 expression, however, measured by mRNA abundance, was much lower in the early gestation than in the term amnion (Fig. 4C).

\section{Methylation of steroid receptor genes}

The proportions of methylated copies of the GR, PGR and ESR1 genes are presented in Fig. 5. Variable proportions were detected both in the amnion (Fig. 5A; GR, 0.25-28.58\%; PGR, 0.03-26.18\%; ESR1, 6.9-50.935\%) and in the decidua (Fig. 5B; GR, 0.3-14.82\%; PGR, 0.13-3.61\%; ESR1, 7.41-41.94\%). There were no significant differences between the gestational groups; however, the variance of methylated ESR1 copy proportions increased significantly with advancing pregnancy in the amnion. Methylated copy proportions were significantly different between the steroid receptor genes in the order of $G R=P G R<E S R 1$ in amnion and $P G R<G R<$ ESR1 in the decidua (with gestational groups pooled).

All combinations of GR, PGR and ESR1 densely methylated copy proportions correlated significantly in individual amnion samples (Fig. 6). In individual decidua samples, only PGR- and ESR1-methylated copy proportions showed significant correlation (Fig. 7).

\section{DNMT expression in amnion and decidua}

The methyltransferase isoenzymes DNMT3A and -3B perform de novo CpG methylation of DNA, while cellspecific meCpG patterns are maintained during DNA replication by DNMT1, which methylates the newly synthesised DNA strand at hemi-methylated CpG sites. Results in Fig. 8 show that mRNAs encoding these enzymes are present in the amnion and the decidua. In the amnion, DNMT1 mRNA levels were significantly different between the gestational groups being highest in early pregnancy and lowest after term labour (KruskalWallis ANOVA corrected for multiple comparisons). DNMT3A mRNA showed relatively robust levels in the amnion in early pregnancy and significantly lower abundance in the term amnion groups. DNMT1

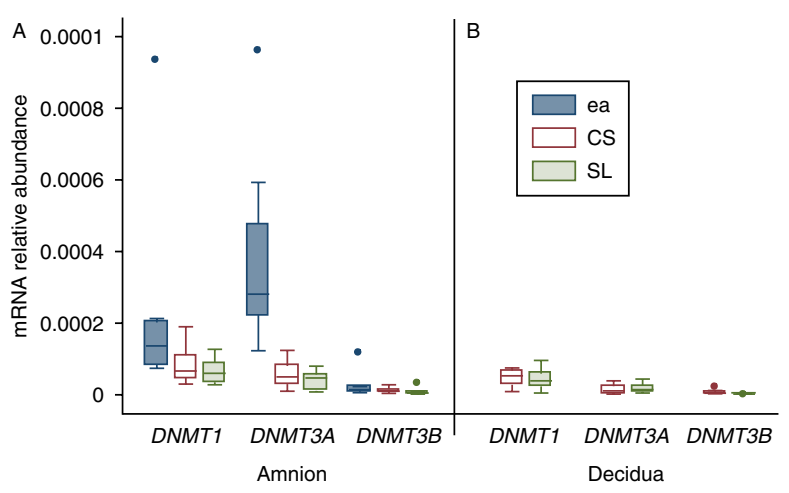

Figure 8

Relative abundance of DNMT1, DNMT3A and DNMT3B mRNAs in amnion (A) and decidua (B). Gestational groups $(n=8$, each) are 11-13 weeks of pregnancy (ea, blue), term elective Caesarean delivery (CS, maroon) and term spontaneous birth (SL, green). Boxes span the 25th-75th percentiles with horizontal lines indicating the median, whiskers showing the range of adjacent values and dots showing the outside values. DNMT1 mRNA levels are significantly higher in ea vs SL and DNMT3A mRNA levels are significantly higher in ea vs SL and CS in the amnion. There are no significant differences in the decidua. Full colour version of this figure available via http://dx.doi.org/10.1530/JME-12-0211. http://jme.endocrinology-journals.org DOI: 10.1530/JME-12-0211
() 2013 Society for Endocrinology Printed in Great Britain 
and - $3 A$ mRNA levels showed no change with labour in the decidua. DNMT3B mRNA abundance values were close to or below the detection limit of our qRT-PCR assay in both tissues.

\section{Discussion}

Understanding the regulation of inflammatory genes in the gestational tissues is critical for unravelling the mechanisms that determine gestational length and underlie pregnancy complications such as preterm birth or post-term pregnancy (Doherty \& Norwitz 2008, MacIntyre et al. 2012). DNA (CpG) methylation has been proposed to participate in this process (Mitchell 2006, Sato \& Mitchell 2006, Wang et al. 2008, Menon et al. 2012, Mitchell et al. 2012), because this epigenetic chromatin modification is involved in establishing, maintaining and altering gene expression patterns during development. In this study, we have analysed the methylation status of four prototypic 'acute inflammatory gene expression signature' genes in the amnion and decidua, which are gestational tissues of fetal and maternal origin respectively. The expression of these genes, PTGS2, BMP2, NAMPT and CXCL2, increases during fetal membrane activation at labour (Haddad et al. 2006, Johnson et al. 2006, Mazaki-Tovi et al. 2008, Li et al. 2011, Lim et al. 2012). Their promoters are rich in CpG motifs, which form clusters called CpG islands. Genome-wide studies have revealed that $\mathrm{CpG}$ island-containing promoters are generally unmethylated with the exception of a few specialised groups of genes (e.g. germ cell-, pluripotencyand developmental-specific genes) that are repressed by CpG island methylation in a tissue- and developmental stage-specific manner (Shen et al. 2007, Weber et al. 2007, Illingworth et al. 2008, Straussman et al. 2009). Promoter hypermethylation has been shown to suppress PTGS2 and BMP2 expression in cancer cells (Song et al. 2001, Wen et al. 2006), suggesting that this chromatin modification may contribute to the suppression of labour-associated inflammatory genes in the gestational tissues during pregnancy. Indeed, we found that variable copy proportions of the studied inflammatory genes were densely methylated in both tissues. It is reasonable to conjecture, therefore, that these gene copies were transcriptionally inactive. Notably, the methylated copy proportions varied but did not exceed $50 \%$ in any tissue sample, suggesting that at least one allele per cell remained unmethylated at the tissue level overall. It must be pointed out that the various cell types present in the tissue samples may have different methylation densities at the studied genes and our Methyl-Profiler analysis reflects the tissue level sum of methylated and unmethylated copy proportions. These unmethylated copies appear responsible for the regulated expression of the genes, as densely methylated copy proportions did not decrease with the increasing levels of gene expression at term and did not correlate with expression in individuals, as demonstrated in the case of the PTGS2. The high resolution analysis of PTGS2 promoter $\mathrm{CpG}$ methylation by bisulphite sequencing also supported the conclusion that the hypomethylated gene copies participate in the gestational control of PTGS2 expression in amnion. The methylation analysis of steroid receptor genes yielded similar results. The GR, $P G R$ and ESR1 genes possess CpG island-containing promoters, and $\mathrm{CpG}$ methylation has been shown to reduce steroid receptor expression in cancer cells and in response to environmental conditions (Sasaki et al. 2001, O'Doherty et al. 2002, Champagne et al. 2006, Wu et al. 2008, McGowan et al. 2009). Nuclear steroid receptor levels have not been reported to change in the gestational membranes during pregnancy; however, expression shows tissuespecific differences with decidua expressing all three receptors while amnion lacks detectable PGR and ESR1 mRNA or protein (Padayachi et al. 1987, 1990, Merlino et al. 2009). These tissue-specific differences were not reflected by the methylation status of the receptor genes, which showed variable densely methylated copy proportions of up to $50.9 \%$ and overall highest methylation of the ESR1 in both tissues.

The absence of significant gestational differences in the overall methylation status (median densely methylated copy proportions) suggests that the methylation levels of the studied genes is established before the gestational age of the early pregnancy group of our amnion sample cohort (ea, 11-17 weeks). This conclusion is supported by the lack in any sample of intermediately methylated gene copies representing the transition between the sparsely and densely methylated states (Holemon et al. 2007). Further, DNA methyltransferase (DNMT1 and -3A) expression was most pronounced in the early gestation amnions, which was the sample group nearest to the proposed methylation event. Methylation is influenced by DNA sequence context, as indicated by the significant differences between the methylated copy proportions of genes in both tissues. The wide variation of densely methylated gene copy proportions among individuals suggests that individual circumstances have major influence on methyltransferase action at the time when methylation patterns are established in the embryos. Strong support for this notion is provided by

Published by Bioscientifica Ltd. 
the correlation of densely methylated copy proportions between all inflammatory and steroid receptor genes in individual amnions (Figs 2 and 6). At the same time, the tendency for increased variance of methylation during pregnancy, reaching statistical significance in the case of CXCL2 and ESR1 in the amnion Figs $1 \mathrm{~A}$ and 5A), is suggestive of plasticity resulting in increased methylated copy proportions in some individuals during later stages of the pregnancy. Correlation of methylation levels was not observed between all genes in the decidua, which is a maternal tissue with a potentially long history of exposure to modifying factors.

In conclusion, we have determined by DNA methylation density analysis that individually varying proportions of $\mathrm{CpG}$ island-containing inflammatory and steroid receptor gene copies are methylated in the human amnion and decidua at high levels known to repress gene activity. Methylation in the amnion happens predominantly in the first trimester influenced by sequence context and affected strongly by individual circumstances. The proportion of densely methylated gene copies has no influence on either the gestational changes or the tissue specificity of gene expression. It must be noted, however, that all tissue samples in our study were obtained from uncomplicated, normal pregnancies. Further studies are needed to establish whether changing methylation of inflammatory, steroid receptor or other disease-associated genes contributes to aberrant gene expression in pathological pregnancies.

\section{Declaration of interest}

The authors declare that there is no conflict of interest that could be perceived as prejudicing the impartiality of the research reported.

\section{Funding}

This work was supported by the National Health and Medical Research Council of Australia (Project Grant 510746) and the John Hunter Hospital Charitable Trust (2009).

\section{Acknowledgements}

The authors gratefully acknowledge support by A/Prof. Andrew Bisits for the clinical aspects of the work.

\section{References}

Berger SL, Kouzarides T, Shiekhattar R \& Shilatifard A 2009 An operational definition of epigenetics. Genes and Development 23 781-783. (doi:10.1101/gad.1787609)
Bird A 2007 Perceptions of epigenetics. Nature 447 396-398. (doi:10.1038/ nature05913)

Bogdanovic O \& Veenstra GJ 2009 DNA methylation and methyl-CpG binding proteins: developmental requirements and function. Chromosoma 118 549-565. (doi:10.1007/s00412-009-0221-9)

Champagne FA, Weaver IC, Diorio J, Dymov S, Szyf M \& Meaney MJ 2006 Maternal care associated with methylation of the estrogen receptor- $\alpha 1 b$ promoter and estrogen receptor- $\alpha$ expression in the medial preoptic area of female offspring. Endocrinology 147 2909-2915. (doi:10.1210/ en.2005-1119)

Doherty L \& Norwitz ER 2008 Prolonged pregnancy: when should we intervene? Current Opinion in Obstetrics and Gynecology 20 519-527. (doi:10.1097/GCO.0b013e328314b6f8)

Ehrlich M 2003 Expression of various genes is controlled by DNA methylation during mammalian development. Journal of Cellular Biochemistry 88 899-910. (doi:10.1002/jcb.10464)

Guo CM, Kasaraneni N, Sun K \& Myatt L 2012 Cross talk between PKC and CREB in the induction of COX-2 by PGF $2 \alpha$ in human amnion fibroblasts. Endocrinology 153 4938-4945. (doi:10.1210/en.2012-1441)

Haddad R, Tromp G, Kuivaniemi H, Chaiworapongsa T, Kim YM, Mazor M \& Romero R 2006 Human spontaneous labor without histologic chorioamnionitis is characterized by an acute inflammation gene expression signature. American Journal of Obstetrics and Gynecology 394 e391-e324. (doi:10.1016/j.ajog.2005.08.057)

Holemon H, Korshunova Y, Ordway JM, Bedell JA, Citek RW, Lakey N, Leon J, Finney M, McPherson JD \& Jeddeloh JA 2007 MethylScreen: DNA methylation density monitoring using quantitative PCR. Biotechniques 43 683-693. (doi:10.2144/000112597)

Illingworth R, Kerr A, Desousa D, Jorgensen H, Ellis P, Stalker J, Jackson D, Clee C, Plumb R, Rogers J et al. 2008 A novel CpG island set identifies tissue-specific methylation at developmental gene loci. PLoS Biology 6 e22. (doi:10.1371/journal.pbio.0060022)

Jiang ZY, Guo YY, Ren HB, Zou YF, Fan MS, Lv Y, Han P, De W \& Sun LZ 2012 Tumor necrosis factor (TNF)- $\alpha$ upregulates progesterone receptor-A by activating the NF-kappaB signaling pathway in human decidua after labor onset. Placenta 33 1-7. (doi:10.1016/j.placenta.2011.09.004)

Johnson RF, Mitchell CM, Giles WB, Walters WA \& Zakar T 2002 The in vivo control of prostaglandin $\mathrm{H}$ synthase- 2 messenger ribonucleic acid expression in the human amnion at parturition. Journal of Clinical Endocrinology and Metabolism 87 2816-2823. (doi:10.1210/jc.87.6.2816)

Johnson RF, Mitchell CM, Giles WB, Bisits A \& Zakar T 2006 Mechanisms regulating prostaglandin $\mathrm{H} 2$ synthase- 2 mRNA level in the amnion and chorion during pregnancy. Journal of Endocrinology 188 603-610. (doi:10.1677/joe.1.06488)

Klose RJ \& Bird AP 2006 Genomic DNA methylation: the mark and its mediators. Trends in Biochemical Sciences 31 89-97. (doi:10.1016/j.tibs. 2005.12.008)

Li R, Ackerman WEt, Summerfield TL, Yu L, Gulati P, Zhang J, Huang K, Romero R \& Kniss DA 2011 Inflammatory gene regulatory networks in amnion cells following cytokine stimulation: translational systems approach to modeling human parturition. PLoS ONE 6 e20560. (doi:10.1371/journal.pone.0020560)

Lim S, MacIntyre DA, Lee YS, Khanjani S, Terzidou V, Teoh TG \& Bennett PR 2012 Nuclear factor kappa B activation occurs in the amnion prior to labour onset and modulates the expression of numerous labour associated genes. PLOS ONE 7 e34707. (doi:10.1371/journal.pone. 0034707)

Livak KJ \& Schmittgen TD 2001 Analysis of relative gene expression data using real-time quantitative PCR and the $2(-$ Delta Delta $C(\mathrm{~T}))$ method. Methods 25 402-408. (doi:10.1006/meth.2001.1262)

MacIntyre DA, Sykes L, Teoh TG \& Bennett PR 2012 Prevention of preterm labour via the modulation of inflammatory pathways. Journal of Maternal-Fetal \& Neonatal Medicine 25 (Suppl 1) 17-20. (doi:10.3109/ 14767058.2012.666114)

Marvin KW, Keelan JA, Eykholt RL, Sato TA \& Mitchell MD 2002 Use of cDNA arrays to generate differential expression profiles for 
inflammatory genes in human gestational membranes delivered at term and preterm. Molecular Human Reproduction 8 399-408. (doi:10.1093/molehr/8.4.399)

Mazaki-Tovi S, Romero R, Kusanovic JP, Erez O, Gotsch F, Mittal P, Than NG, Nhan-Chang CL, Hamill N, Vaisbuch E et al. 2008 Visfatin/Pre-B cell colony-enhancing factor in amniotic fluid in normal pregnancy, spontaneous labor at term, preterm labor and prelabor rupture of membranes: an association with subclinical intrauterine infection in preterm parturition. Journal of Perinatal Medicine 36 485-496. (doi:10.1515/JPM.2008.084)

McGowan PO, Sasaki A, D'Alessio AC, Dymov S, Labonte B, Szyf M, Turecki G \& Meaney MJ 2009 Epigenetic regulation of the glucocorticoid receptor in human brain associates with childhood abuse. Nature Neuroscience 12 342-348. (doi:10.1038/nn.2270)

Menon R, Conneely KN \& Smith AK 2012 DNA methylation: an epigenetic risk factor in preterm birth. Reproductive Sciences 19 6-13. (doi:10.1177/ 1933719111424446)

Merlino A, Welsh T, Erdonmez T, Madsen G, Zakar T, Smith R, Mercer B $\&$ Mesiano $S 2009$ Nuclear progesterone receptor expression in the human fetal membranes and decidua at term before and after labor. Reproductive Sciences 16 357-363. (doi:10.1177/1933719108328616)

Mitchell MD 2006 Unique suppression of prostaglandin h synthase-2 expression by inhibition of histone deacetylation, specifically in human amnion but not adjacent choriodecidua. Molecular Biology of the Cell 17 549-553. (doi:10.1091/mbc.E05-08-0818)

Mitchell BF \& Powell WA 1984 Progesterone production by human fetal membranes: an in vitro incubation system for studying hormone production and metabolism. American Journal of Obstetrics and Gynecology 148 303-309.

Mitchell C, Johnson R, Bisits A, Hirst J \& Zakar T 2011 PTGS2 (prostaglandin endoperoxide synthase-2) expression in term human amnion in vivo involves rapid mRNA turnover, polymerase-II 5'-pausing, and glucocorticoid transrepression. Endocrinology 152 2113-2122. (doi:10.1210/en.2010-1327)

Mitchell MD, Ponnampalam AP \& Rice GE 2012 Epigenetic regulation of cytokine production in human amnion and villous placenta. Mediators of Inflammation 2012 159709. (doi:10.1155/2012/159709)

O'Doherty AM, Church SW, Russell SE, Nelson J \& Hickey I 2002 Methylation status of oestrogen receptor- $\alpha$ gene promoter sequences in human ovarian epithelial cell lines. British Journal of Cancer 86 282-284. (doi:10.1038/sj.bjc.6600028)

Ordway JM, Bedell JA, Citek RW, Nunberg A, Garrido A, Kendall R, Stevens JR, Cao D, Doerge RW, Korshunova Y et al. 2006 Comprehensive DNA methylation profiling in a human cancer genome identifies novel epigenetic targets. Carcinogenesis $\mathbf{2 7}$ 2409-2423. (doi:10.1093/carcin/bgl161)

Padayachi T, Pegoraro RJ, Hofmeyr J, Joubert SM \& Norman RJ 1987 Decreased concentrations and affinities of oestrogen and progesterone receptors of intrauterine tissue in human pregnancy. Journal of Steroid Biochemistry 26 473-479. (doi:10.1016/0022-4731(87)90059-8)

Padayachi T, Pegoraro RJ, Rom L \& Joubert SM 1990 Enzyme immunoassay of oestrogen and progesterone receptors in uterine and intrauterine tissue during human pregnancy and labour. Journal of Steroid Biochemistry and Molecular Biology 37 509-511. (doi:10.1016/ 0960-0760(90)90394-Z)

Sasaki M, Dharia A, Oh BR, Tanaka Y, Fujimoto S \& Dahiya R 2001 Progesterone receptor B gene inactivation and CpG hypermethylation in human uterine endometrial cancer. Cancer Research 61 97-102.
Sato TA \& Mitchell MD 2006 Molecular inhibition of histone deacetylation results in major enhancement of the production of IL- $1 \beta$ in response to LPS. American Journal of Physiology. Endocrinology and Metabolism 290 E490-E493. (doi:10.1152/ajpendo.00406.2005)

Shankar R, Johnson MP, Williamson NA, Cullinane F, Purcell AW, Moses EK \& Brennecke SP 2010 Molecular markers of preterm labor in the choriodecidua. Reproductive Sciences 17 297-310. (doi:10.1177/ 1933719109353454)

Shen L, Kondo Y, Guo Y, Zhang J, Zhang L, Ahmed S, Shu J, Chen X, Waterland RA \& Issa JP 2007 Genome-wide profiling of DNA methylation reveals a class of normally methylated CpG island promoters. PLoS Genetics 3 2023-2036. (doi:10.1371/journal.pgen. 0030181)

Song SH, Jong HS, Choi HH, Inoue H, Tanabe T, Kim NK \& Bang YJ 2001 Transcriptional silencing of cyclooxygenase- 2 by hyper-methylation of the $5^{\prime} \mathrm{CpG}$ island in human gastric carcinoma cells. Cancer Research $\mathbf{6 1}$ $4628-4635$.

Straussman R, Nejman D, Roberts D, Steinfeld I, Blum B, Benvenisty N, Simon I, Yakhini Z \& Cedar H 2009 Developmental programming of $\mathrm{CpG}$ island methylation profiles in the human genome. Nature Structural and Molecular Biology 16 564-571. (doi:10.1038/nsmb.1594)

Sun M, Ramirez M, Challis JR \& Gibb W 1996 Immunohistochemical localization of the glucocorticoid receptor in human fetal membranes and decidua at term and preterm delivery. Journal of Endocrinology 149 243-248. (doi:10.1677/joe.0.1490243)

Tate PH \& Bird AP 1993 Effects of DNA methylation on DNA-binding proteins and gene expression. Current Opinion in Genetics \& Development 3 226-231. (doi:10.1016/0959-437X(93)90027-M)

Wang H, Ogawa M, Wood JR, Bartolomei MS, Sammel MD, Kusanovic JP, Walsh SW, Romero R \& Strauss JF III 2008 Genetic and epigenetic mechanisms combine to control MMP1 expression and its association with preterm premature rupture of membranes. Human Molecular Genetics 17 1087-1096. (doi:10.1093/hmg/ddm381)

Weber M, Hellmann I, Stadler MB, Ramos L, Paabo S, Rebhan M \& Schubeler D 2007 Distribution, silencing potential and evolutionary impact of promoter DNA methylation in the human genome. Nature Genetics 39 457-466. (doi:10.1038/ng1990)

Weih F, Nitsch D, Reik A, Schutz G \& Becker PB 1991 Analysis of CpG methylation and genomic footprinting at the tyrosine aminotransferase gene: DNA methylation alone is not sufficient to prevent protein binding in vivo. EMBO Journal 10 2559-2567.

Wen XZ, Akiyama Y, Baylin SB \& Yuasa Y 2006 Frequent epigenetic silencing of the bone morphogenetic protein 2 gene through methylation in gastric carcinomas. Oncogene 25 2666-2673. (doi:10.1038/sj.onc.1209297)

Wu Y, Starzinski-Powitz A \& Guo SW 2008 Prolonged stimulation with tumor necrosis factor- $\alpha$ induced partial methylation at PR-B promoter in immortalized epithelial-like endometriotic cells. Fertility and Sterility 90 234-237. (doi:10.1016/j.fertnstert.2007.06.008)

Zakar T \& Hertelendy F 2007 Progesterone withdrawal: key to parturition. American Journal of Obstetrics and Gynecology 196 289-296. (doi:10.1016/j.ajog.2006.09.005)

Zhu XO, Yang Z, Guo CM, Ni XT, Li JN, Ge YC, Myatt L \& Sun K 2009 Paradoxical stimulation of cyclooxygenase- 2 expression by glucocorticoids via a cyclic AMP response element in human amnion fibroblasts. Molecular Endocrinology 23 1839-1849. (doi:10.1210/ me.2009-0201)

Received in final form 25 January 2013

Accepted 7 February 2013

Accepted Preprint published online 7 February 2013 http://jme.endocrinology-journals.org DOI: 10.1530/JME-12-0211
() 2013 Society for Endocrinology Printed in Great Britain 